\title{
Survival of a case of Bacillus cereus meningitis with brain abscess presenting as immune reconstitution syndrome after febrile neutropenia - a case report and literature review-
}

\author{
Yusuke Koizumi ${ }^{1,2^{*}}$ (D), Takafumi Okuno ${ }^{2}$, Hitoshi Minamiguchi ${ }^{2}$, Keiko Hodohara ${ }^{2}$, Hiroshige Mikamo ${ }^{1}$ and
} Akira Andoh ${ }^{2}$

\begin{abstract}
Background: Bacillus cereus sometimes causes central nervous system infection, especially in compromised hosts. In cases of meningitis arising during neutropenia, CSF abnormalities tend to be subtle and can be easily overlooked, and mortality rate is high. We report a survived case of $B$. cereus meningitis/brain abscess in severe neutropenia, presenting as immune reconstitution syndrome.
\end{abstract}

Case presentation: A 54-year-old Japanese female with acute myelogenous leukemia developed B. cereus bacteremia and meningitis during consolidation chemotherapy. At the onset, she presented with mild meningism. She had marked leukocytopenia (WBC <100/ $\mathrm{LL}$, neutrophils $0 / \mu \mathrm{L}$ ) and lumbar puncture yielded only mild pleocytosis. She was transferred to intensive care unit, and meropenem, linezolid and vancomycin was started. With intensive therapy, she recovered and once became afebrile. On day 19, however, her fever, meningism and consciousness level dramatically worsened despite recovery of bone marrow function. The antimicrobial chemotherapy was continued and finally she was cured with no complications.

Conclusions: With early diagnosis and prompt initiation and of antibiotics, the case was successfully treated without any sequelae. It is important to remember that, even under optimal antimicrobial therapy, bone marrow recovery can cause transient reaggravation of the disease. In such cases, timely and appropriate evaluation should be done to make the clinical decision to change, continue, or intensify treatment.

Keywords: Bacillus cereus, Meningitis, Bacteremia, Febrile neutropenia, Immune reconstitution syndrome

\section{Background}

Bacillus cereus is a Gram positive, aerobic facultative, spore-forming, rod-shaped bacterium. It is motile, catalase positive and ubiquitous, found in air, soil, water, and food [1]. Because of the ubiquitous distribution of $B$. cereus in food products, the bacterium is ingested in small numbers and becomes part of the transitory human intestinal flora [2]. Traditionally, the detection of Bacillus species in sterile samples has been regarded as contamination. However, the organism has the potential to cause severe infectious diseases in immunocompromised hosts [1]. Herein, we report a case of $B$. cereus meningitis with brain abscess, arising in the setting of neutropenia, and presenting as immune reconstitution syndrome after bone marrow recovery.

\section{Case presentation}

A 54-year-old Japanese female was diagnosed with acute myeloid leukemia (AML). Complete remission was

* Correspondence: ykoizumi@aichi-med-u.ac.jp

${ }^{1}$ Department of Clinical Infectious Diseases, Aichi Medical University Hospital,

1-1 Yazakokarimata, Nagakute, Aichi 480-1195, Japan

2Department of Hematology, Shiga University of Medical Science, Otsu,

Shiga, Japan

(c) The Author(s). 2020 Open Access This article is distributed under the terms of the Creative Commons Attribution 4.0 International License (http://creativecommons.org/licenses/by/4.0/), which permits unrestricted use, distribution, and 
achieved after induction chemotherapy, but 14 months later the disease relapsed. During the re-induction chemotherapy (FLAGM; fludarabine, cytarabine, granulocyte colony stimulating factor, and mitoxantrone), she experienced severe septic shock caused by Klebsiellla pneumoniae bacteremia requiring intensive care. During the consolidation therapy (high dose cytarabine), oral polymyxin $B$, sulfamethoxazole/trimethoprim, voriconazole, and acyclovir were administered as prophylaxis.

On day 18 of consolidation chemotherapy (day 1 of infection), she complained of fever and chills. Meropenem $3 \mathrm{~g} /$ day was started after blood culture sampling. On day 2, headache and nausea appeared. Diarrhea was absent, and the vital signs were as follows: blood pressure 124/ $67 \mathrm{mmHg}$, heart rate $86 \mathrm{bpm}$, and body temperature $39.5^{\circ} \mathrm{C}$. At this time, she was conscious and lucid. Neurologically, no abnormal focal signs, including nuchal rigidity, were noted. Laboratory tests showed marked leukocytopenia (WBC $<100 / \mu \mathrm{L}$, neutrophils $0 / \mu \mathrm{L}$ ) with slight C-reactive protein elevation $(1.32 \mathrm{mg} / \mathrm{dL})$. The blood culture detected a Gram-positive rod-shaped bacterium on day 2 , and the pathogen was identified as $B$. cereus on day 4 . The strain was resistant to penicillin and quinolones, but sensitive to carbapenems, vancomycin, and linezolid.

On day 3, disorientation, slurred speech, and confusion appeared. Slight nuchal rigidity was observed, and the neck flexion test was positive. Although meningitis was suggested, lumbar puncture was not performed because of severe thrombocytopenia $(21,000 / \mu \mathrm{L})$. Instead, linezolid (1200 mg/day), vancomycin (targeted trough of $20 \mathrm{mg} / \mathrm{dL}$ ), and acyclovir $(30 \mathrm{mg} / \mathrm{kg} /$ day $)$ were administered in addition to high dose meropenem ( $6 \mathrm{~g} /$ day).

On day 5 , she was transferred to the intensive care unit because of shock. At this time, lumbar puncture yielded the following results: opening pressure: 18 $\mathrm{cmH}_{2} \mathrm{O}$; cells: $43 / \mathrm{mm}^{3}$ (mononuclear cells dominant, with no abnormal cells); glucose: $31 \mathrm{mg} / \mathrm{dL}$; protein: 155 $\mathrm{mg} / \mathrm{dL}$; negative for HSV-DNA, VZV-DNA, CMV-DNA, HHV-6 DNA, Cryptococcus-Antigen and WT-1 (Wilms Tumor-1). Cerebrospinal fluid (CSF) culture was negative, but $B$. cereus PCR was positive, leading to the diagnosis as $B$. cereus meningitis.

With inotropic agents, deep sedation, and antimicrobials, she recovered and became afebrile. On day 19, however, her fever, meningism and consciousness level dramatically worsened despite recovery of bone marrow function. The CSF findings revealed markedly increased cells $\left(2040\right.$ cells $\left./ \mathrm{mm}^{3}\right)$, and decreased glucose level (12 $\mathrm{mg} / \mathrm{dL}$ ). The CSF culture and PCR for B. cereus were both negative, and other diseases were excluded by the aforementioned examinations. Therefore, in concert with the increased leukocytes in peripheral blood and CSF, it was suggestive of immune reconstitution syndrome after $B$. cereus meningitis. The gadolinium enhanced magnetic resonance imaging (MRI) performed on day 15 had already detected meningeal thickening and several ring enhancement lesions. Glucocorticoid administration was not used to treat immune reconstitution syndrome. Meropenem, vancomycin, and linezolid were continued for 26,40 , and 45 days, respectively. They were stopped after CSF and MRI findings were confirmed to be normalized. On day 90, she was discharged to her home without any sequela, and her AML remains in remission for 5 years.

\section{Discussion and conclusions}

Central nervous system infections caused by $B$. cereus can be classified as three diseases: 1) postsurgical meningitis, ventriculitis or brain abscess, which can occur several days after a surgical procedure and often affects devices [3]; 2) neonatal meningitis or encephalitis occurring in premature neonates at 7 days of age (median, range 1-49 days) [4]; 3) necrotizing meningitis or

Table 1 Three Types of Central Nervous System Bacillus cereus Infection

\begin{tabular}{llll}
\hline & $\begin{array}{l}\text { Post-Surgical Procedure/Device } \\
\text { Infection }\end{array}$ & Neonatal Infection & Severe Neutropenia \\
\hline Risk Population & Ommaya reservoir & Premature birth: 32 (27-36) weeks & WBC count <100/uL \\
& Post intrathecal injection & Low body weight infant:1500 (830-3760) g Induction therapy against AML \\
Disease Onset & Several days after procedures & $7(1-49)$ days after birth & Around 10 days of neutropenia \\
Mode of Infection & Meningitis & Meningoencephalitis & Necrotizing meningoencephalitis \\
& Ventriculitis & & Cerebral hemorrhage \\
Clinical Course and Prognosis & Responds well to antimicrobial therapy & Progresses within hours & Subarachnoid hemorrhage \\
& & Leads to death within days & Progresses within hours \\
Cerebrospinal Fluid Findings & Up to $10^{5}$ cells $/ \mathrm{mm}^{3}$ & Around $10^{2-3}$ cells $/ \mathrm{mm}^{3}$ & Leads to death within days \\
Mortality rate & Low & $75 \%(12 / 14$ cases $)$ & Around $10^{2}$ cells $/ \mathrm{mm}^{3}$ \\
References & 3 & 3,4 & $79 \%$ (11/14 cases) \\
\hline
\end{tabular}




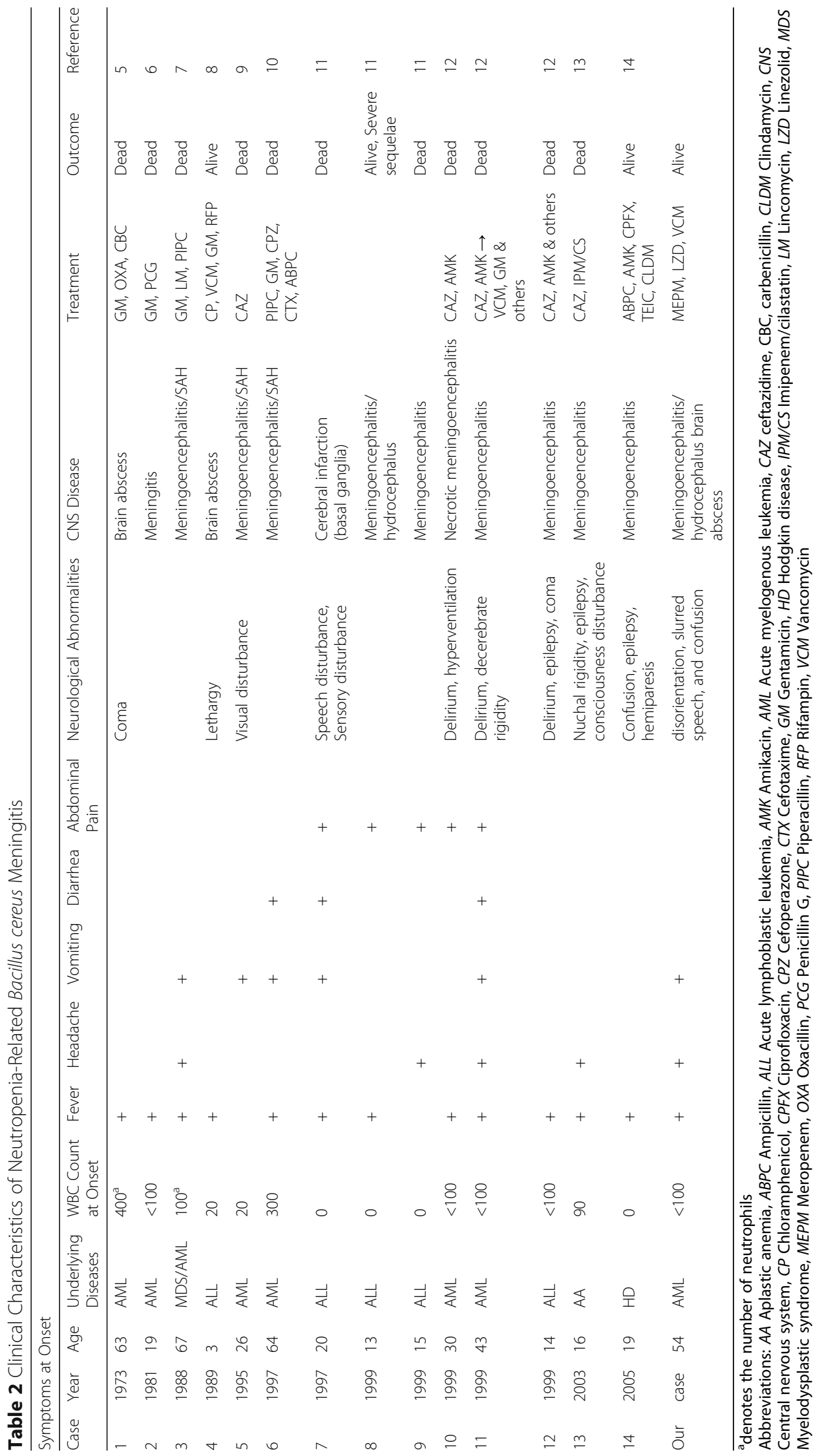


hemorrhage in cases of severe neutropenia, predominantly affecting patients with leukemia (Table 1) [3-14].

While postsurgical infections typically resolve in spite of marked CSF pleocytosis, in the order of $10^{5}$ cells/ $\mathrm{mm}^{3}$, the latter two infection types have very poor prognoses with mortality rate greater than $75 \%$. Notably, in many cases of these two malicious diseases, CSF cell counts are usually less than $10^{2}$ cells $/ \mathrm{mm}^{3}$.

Fourteen cases of neutropenia-associated $B$. cereus meningitis have been reported so far (Table 2). All but one case had hematological malignancies (AML: 6, acute lymphoblastic leukemia: 7, myelodysplastic syndrome: 1 , aplastic anemia: 1) and all had severe neutropenia of less than $500 / \mu \mathrm{L}$ at the onset of disease. Moreover, $79 \%$ had less than $100 / \mu \mathrm{L}$ blood leukocytes, suggesting a role for severe neutropenia in the pathogenesis of this disease. The cases demonstrated mild or absent CSF pleocytosis, which is considered to be a result of both the severely immunodeficient state of the patient and the character of $B$. cereus infection in itself, which causes little inflammatory reaction [15].

Our case shared common features with previous reports such as severe neutropenia at the onset of meningitis and the complication of brain abscesses. While those are typical findings of neutropenia associated $B$. cereus meningitis, there are two particular features of this report. First, with an early diagnosis and administration of a contemporary antimicrobial regimen, we were

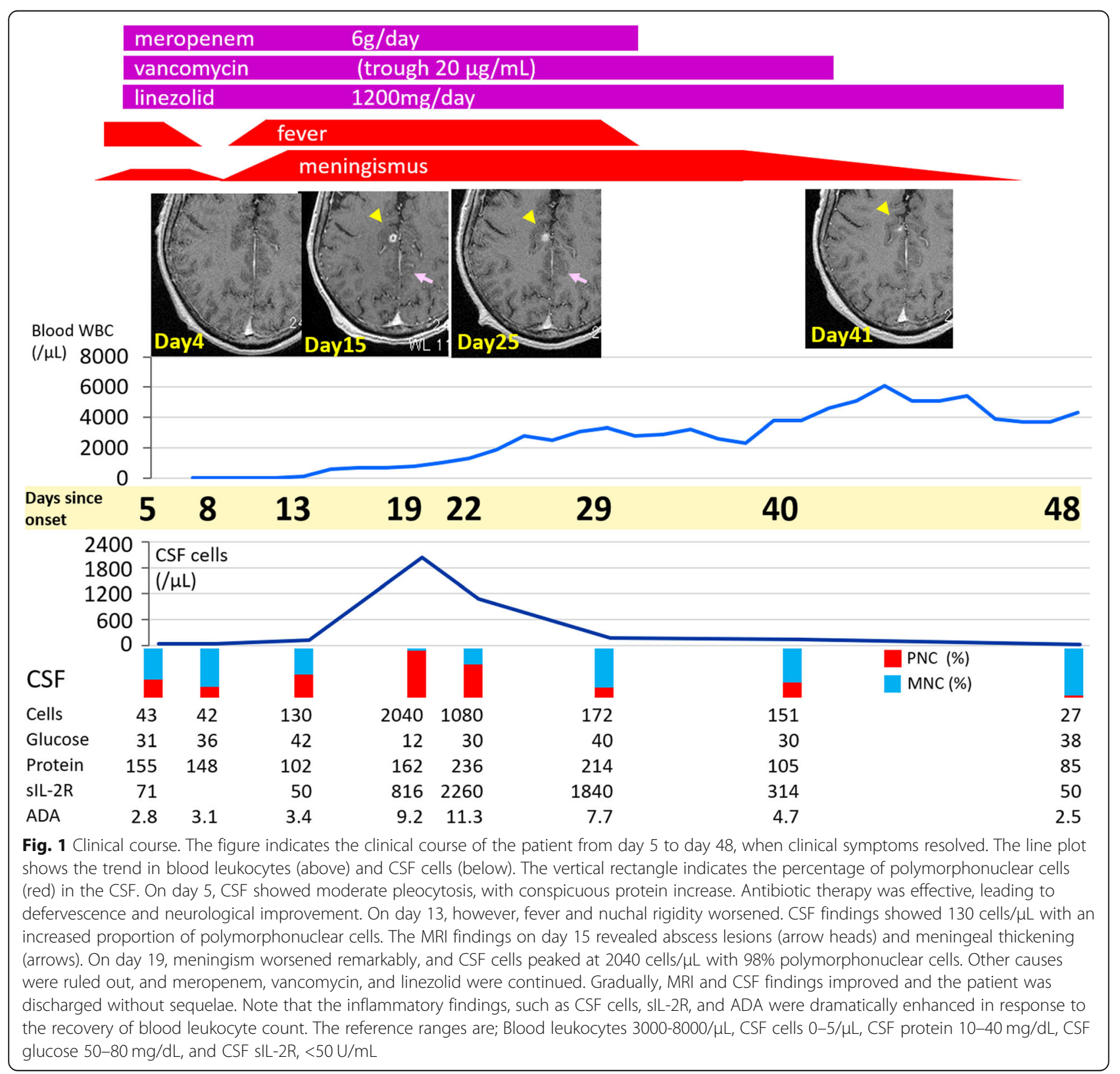


able to cure the disease without any complications. The regimen contained antibiotics with good penetrance, including linezolid, high dose meropenem, and a well-controlled dose of vancomycin that achieved a serum trough level of $20 \mu \mathrm{g} / \mathrm{mL}$. This well-structured regimen was started immediately after the onset of meningitis, though the physical findings were subtle in the early phase, and CSF findings at day 5 showed only a moderate level of pleocytosis. This early diagnosis is crucial for the rapid initiation of intensive antimicrobial therapy.

Second, we were able to closely track the CSF and MRI findings with the recovery of hematopoiesis. The patient's meningitis symptoms were improving until day 19 , when neutrophils rapidly increased. With the recovery of neutrophil count, a dramatic worsening of fever, consciousness and meningism was demonstrated. This could be considered as a type of immune reconstitution syndrome, though the term originally denoted the recovery of cellular immunity from AIDS or other immunosuppressive states. As shown in Fig. 1, we serially observed parameters of cellular immunity as well as neutrophil count. Interestingly, the severity of meningitis symptoms clearly synchronized with the blood neutrophil count, and the correlation is even more dramatic for CSF cells, CSF soluble interleukin-2 receptor (sIL-2R), and CSF adenosine deaminase (ADA). On day 19, the vast majority of CSF cells were polymorphonuclear cells (neutrophils). Later, CSF, sIL-2R and ADA increased, indicating that a typical inflammation cascade was ongoing. As differential diagnosis, other infections or an intracranial recurrence of AML were considered, but negative culture, cytology and clinical course were indicative of $B$. cereus meningitis. Therefore, we continued the antibiotics and the symptoms gradually improved.

In conclusion, we experienced a case of B. cereus meningitis with brain abscess during severe neutropenia from which the patient survived. With serial measurement of inflammatory / immunological markers, our report described the phenomenon resembling immune reconstitution syndrome, and we also proved that contemporary antimicrobial regimens can cure this severe disease. In cases of meningitis arising during neutropenia, CSF abnormalities tend to be subtle and can be easily overlooked. Because immediate diagnosis is crucial for survival, clinicians should be able to carefully recognize the symptoms and interpret the clinical data in order to rapidly initiate intensive treatment. Furthermore, it is important to remember that bone marrow recovery can cause transient reaggravation of the disease, even under optimal antimicrobial therapy. In such cases, timely and appropriate evaluation should be done to make the clinical decision to change, continue, or intensify treatment.

\section{Abbreviations}

ADA: Adenosine deaminase; AIDS: Acquired immunodeficiency syndrome; AML: Acute myeloid leukemia; CMV: Cytomegalovirus; CSF: Cerebrospinal fluid; FLAGM: Fludarabine, cytarabine, glanulocyte colony stimulating factor, and mitoxantrone combined therapy; HHV-6: Human herpes virus-6; HSV: Herpes simplex virus; LZD: Linezolid; MEPM: Meropenem;

MNC: Mononuclear cells; PNC: Polymorphonuclear cells; sIL-2R: Soluble interleukin-2 receptor; VCM: Vancomycin; VZV: Varicella zoster virus; WBC: White blood cells

\section{Acknowledgements \\ None to declare.}

\section{Authors' contributions}

YK wrote this paper. YK, TO, HM, and KH contributed to diagnosis and clinical decision for treatment. HM and AA contributed in giving advice from the point of Microbiology, and Immunology, respectively. All authors reviewed the manuscript. All Authors read and approved the final version of this manuscript.

Funding

No funding was obtained for this study.

\section{Availability of data and materials}

The authors are ready to provide the data in response to the need.

\section{Ethics approval and consent to participate}

Informed consent was obtained from the patient after verbal and written information provision. All the procedures have been performed in accordance with the ethical standards laid down in the 1964 Declaration of Helsinki and its later amendments.

\section{Consent for publication}

We have confirmed that the participant gave written consent for her personal or clinical details along with any identifying images to be published in this study.

\section{Competing interests}

The authors declare that they have no competing interets.

Received: 28 October 2019 Accepted: 30 December 2019

Published online: 06 January 2020

References

1. Bottone EJ. Bacillus cereus, a volatile human pathogen. Clin Microbiol Rev. 2010;23:382-98.

2. Turnbull PCB, Kramer JM. Intestinal carriage of Bacillus cereus: fecal isolation studies in three population groups. J Hyg (Lond). 1985;95:629-38.

3. Stevens MP, Elam K, Bearman G. Meningitis due to Bacillus cereus: a case report and review of the literature. Can J Infect Dis Med Microbiol. 2012;23: e16-9.

4. Manickam N, Knorr A, Muldrew KL. Neonatal meningoencephalitis caused by Bacillus cereus. Pediatr Infect Dis J. 2008;27:843-6.

5. Inde DC, Armstrong D. Clinical spectrum of infection due to Bacillus species. Am J Med. 1973;55:839-45.

6. Colpin GG, Guiot HF, Simonis RF, Zwaan FE. Bacillus cereus meningitis in a patient under gnotobiotic care. Lancet. 1981;8248:694-5.

7. Funada H, Uotani C, Machi T, Matsuda T, Nonomura A. Bacillus cereus bacteremia in an adult with acute leukemia. Jpn J Clin Oncol. 1988;18:69-74.

8. Jenson HB, Levy SR, Duncan C, Mcintosh S. Treatment of multiple brain abscesses caused by Bacillus cereus. Pediatr Infect Dis J. 1989;8:795-8.

9. Marley EF, Saini NK, Venkatraman C, Orenstein JM. Fatal Bacillus cereus meningoencephalitis in an adult with acute myelogenous leukemia. South Med J. 1995;88:969-72.

10. Motoi N, Ishida T, Nakano I, Akiyama N, Mitani K, Hirai H, Yazaki Y, Machinami R. Necrotizing Bacillus cereus infection of the meninges without inflammatory reaction in a patient with acute myelogenous leukemia: a case report. Acta Neuropathol. 1997;93:301-5.

11. Gaur AH, Patrick CC, McCullers JA, Flynn PM, Pearson TA, Razzouk Bl, Thompson SJ, Shenep JL. Bacillus cereus bacteremia and meningitis in immunocompromised children. Clin Infect Dis. 2001;32:1456-62. 
12. Musa MO, Al Douri M, Khan S, Shafi T, Al Humaidh A, Al Rasheed AM. Fulminant septicaemic syndrome of Bacillus cereus: three case reports. J Inf Secur. 1999;39:154-6.

13. de Almeida SM, Teive HA, Brandi I, Nabhan SK, Werneck LC, Bittencourt MA, Medeiros CR, Pasquini R, de Mello HH. Fatal Bacillus cereus meningitis without inflammatory reaction in cerebral spinal fluid after bone marrow transplantation. Transplantation. 2003;76:1533-4.

14. Haase R, Sauer H, Dagwadordsch U, Foell J, Lieser U. Successful treatment of Bacillus cereus meningitis following allogenic stem cell transplantation. Pediatr Transplant. 2005;9:338-41.

15. Burdon KL, Davis JS, Wende RD. Experimental infection of mice with Bacillus cereus: studies of pathogenesis and pathologic changes. J Infect Dis. 1967; 117:307-16

\section{Publisher's Note}

Springer Nature remains neutral with regard to jurisdictional claims in published maps and institutional affiliations.

Ready to submit your research? Choose BMC and benefit from:

- fast, convenient online submission

- thorough peer review by experienced researchers in your field

- rapid publication on acceptance

- support for research data, including large and complex data types

- gold Open Access which fosters wider collaboration and increased citations

- maximum visibility for your research: over $100 \mathrm{M}$ website views per year

At BMC, research is always in progress.

Learn more biomedcentral.com/submissions 